\title{
First Case Report of Acquired Pure Red Cell Aplasia Associated with Micafungin
}

\author{
Mayumi Yoshida-Hiroi ${ }^{1}$, Masayuki Koizumi ${ }^{1}$, Reiko Oka ${ }^{1}$, Aki Mitsuda ${ }^{2}$ and Naoki Hiroi ${ }^{3}$
}

\begin{abstract}
A 70-year-old Japanese man with chronic kidney disease under treatment with oral prednisolone for organizing pneumonia developed pulmonary aspergilloma. The patient was started on micafungin (MCFG), with no addition of any other new drug. About 5 weeks later, aggravation of his normocytic anemia associated with a low reticulocyte count was observed. Bone marrow puncture and biopsy revealed intense hypoplasia of the erythroblasts. As there was no evidence of malignancy, human parvovirus B19 infection, autoimmune diseases or hemorrhage, the patient was diagnosed as having acquired pure red cell aplasia (PRCA). The anemia improved along with an increase of the reticulocyte count to the normal level within 12 weeks of discontinuation of the MCFG therapy. The patient showed no evidence subsequently of any recurrence of the normocytic normochromic anemia or relapse of the PRCA. This is the first reported case of PRCA associated with MCFG.
\end{abstract}

Key words: pure red cell aplasia, micafungin, antifungal drug

(Intern Med 50: 1051-1054, 2011)

(DOI: 10.2169/internalmedicine.50.4303)

\section{Introduction}

Micafungin (MCFG), a candin antifungal agent, was developed from an antifungal lipopeptide isolated from cultures of the dermatophyte, Coleophoma empetri $(1,2)$. It exerts its activity through inhibiting the synthesis of $1,3-\beta$-Dglucan, a major component of the cell wall of fungi $(1,3)$. The drug has been used for the treatment of deep-seated mycoses caused by Aspergillus or Candida species. Adverse reactions to this drug reported to date include symptoms associated with histamine release, e.g., hot flashes, eruption (2.7\%), gastrointestinal symptoms, e.g., nausea, vomiting (about 7\%), and liver dysfunction (1.5\%) (4). In addition, hematological disorders, including leukopenia (1.6\%) (4), eosinophilia $(0.1 \%$ to $<5 \%)$ and neutropenia $(1.1 \%)$, have also been reported as adverse reactions to this drug. In regard to the adverse reactions involving erythrocytes, hemolytic anemia is the only reported disorder to date (5-7), and no case of pure red cell aplasia (PRCA) has been reported.
Deep-seated mycoses are opportunistic infections that occur in patients with some serious underlying diseases or in immunocompromised patients. Because antimicrobial agents often need to be used for prolonged periods of time, careful selection of drugs based on an adequate consideration of the efficacy and adverse reactions is essential.

\section{Case Report}

A 70-year-old Japanese man under treatment with prednisolone (PSL) for organizing pneumonia was admitted to our hospital for the management of a developing pulmonary aspergilloma. We started the patient on MCFG at the dose of $150 \mathrm{mg} / \mathrm{day}$ on hospital day 16 (hemoglobin [Hb] $11.7 \mathrm{~g} /$ dL), without any other new drugs, including diphenylhydantoin, isoniazid, azathioprine or erythropoietin, because progression to chronic necrotizing pulmonary aspergillosis was suspected. On hospital day 44, since the response to the treatment was poor, the dose of MCFG was increased to $300 \mathrm{mg} /$ day. The patient was revealed to have normocytic

\footnotetext{
${ }^{1}$ Department of Internal Medicine, Kawasaki Social Insurance Hospital, Japan, ${ }^{2}$ Department of Pathology, Kawasaki Social Insurance Hospital, Japan and ${ }^{3}$ Division of Diabetes, Metabolism and Endocrinology, Department of Internal Medicine (Omori), Toho University School of Medicine, Japan

Received for publication July 31, 2010; Accepted for publication January 25, 2011

Correspondence to Dr. Naoki Hiroi, n-hiroi@med.toho-u.ac.jp
} 

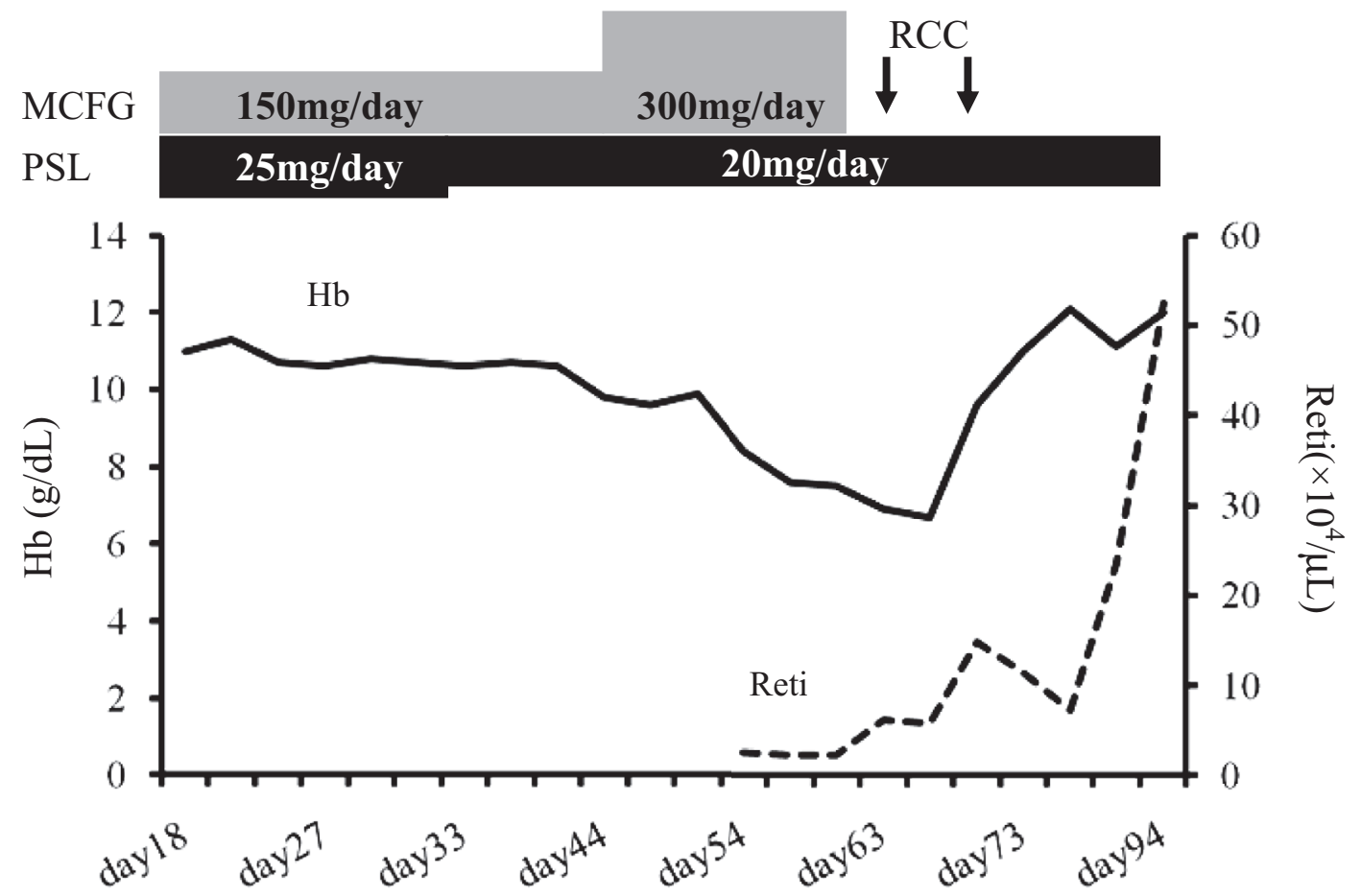

Figure 1. Clinical course of the patient. PSL: prednisolone, MCFG: micafungin, RCC: red cell concentrate, Reti: reticulocyte

anemia at this time $(\mathrm{Hb} 9.8 \mathrm{~g} / \mathrm{dL}$, mean corpuscular volume [MCV] $95 \mathrm{fl})$. Improvement of the aspergilloma was observed on hospital day 53; however, the normocytic anemia persisted. The patient's clinical course is shown in Fig. 1.

At the time of diagnosis of the anemia, the patient was $170 \mathrm{~cm}$ tall, weighed $52 \mathrm{~kg}$, and had a blood pressure of $124 / 78 \mathrm{mmHg}$, heart rate of $72 / \mathrm{min}$, and a body temperature of $36.4^{\circ} \mathrm{C}$. No evidence of abnormalities was found, excluding pallor of the palpebral conjunctiva on physical examination. Biochemically, reduction of the total protein $(4.67 \mathrm{~g} /$ $\mathrm{dL})$ and serum albumin $(2.64 \mathrm{~g} / \mathrm{dL})$ was noted. Liver function was normal, the blood urea nitrogen was $19.5 \mathrm{mg} / \mathrm{dL}$ and the serum creatinine, $1.11 \mathrm{mg} / \mathrm{dL}$ (estimated glomerular filtration rate [eGFR], $51.2 \mathrm{~mL} / \mathrm{min}$ ). In regard to the blood cell counts, the platelet count (PLT) and white blood cell count (WBC) were within normal range (WBC 5,000/ $\mu \mathrm{L}$, neutrophils $70.3 \%$, eosinophils $0.6 \%$, basophils $0.7 \%$, monocytes $9.8 \%$, lymphocytes $18.6 \%$, granular lymphocytes $0 \%$ ); however, there was evidence of normocytic normochromic anemia (red blood cells [RBC] $255 \times 10^{4} / \mu \mathrm{L}, \mathrm{Hb} 8.4 \mathrm{~g} / \mathrm{dL}$, hematocrit [Hct] 24.5\%, MCV $96 \mathrm{fl}$, mean corpuscular hemoglobin $[\mathrm{MCH}] 32.9 \mathrm{pg}$, mean corpuscular hemoglobin concentration [MCHC] 34.3\%) and the reticulocyte count was low, at $1 \%\left(2.55 \times 10^{4} / \mu \mathrm{L}\right)$. The serum erythropoietin level was normal. The direct and indirect antiglobulin tests were negative, as was the serological test for human parvovirus B19 IgM. No evidence of malignant tumor was detected by thoracic/abdominal computed tomography and abdominal ultrasonography. The serum levels of tumor markers such as carcinoembryonic antigen and carbohydrate anti- gen 19-9 were not elevated. Tests for autoantibodies such as antinuclear antibody and rheumatoid factor were negative.

On hospital day 59, further aggravation of the normocytic anemia was observed $(\mathrm{Hb} 7.6 \mathrm{~g} / \mathrm{dL})$, with the reticulocyte count remaining low at $1 \%$. There was no evidence of gastrointestinal hemorrhage, and no decrease of the blood erythropoietin level was noted. A bone marrow smear showed normocytic normochromic anemia with adequate leucocytes and platelets, and no evidence of any abnormal cells (Fig. 2A); the myeloid-erythroid ratio was $97: 1$. Bone marrow biopsy revealed a normal nucleated cell count, no dysplasia of any of the three hematopoietic systems, and no chromosomal abnormalities; however, intense hypoplasia of the erythroblasts was observed (Fig. 2B). The patient was thus diagnosed as having acquired PRCA associated with MCFG, which was the only new drug that had recently been added to his treatment regimen. With continuation of the PSL treatment at $20 \mathrm{mg} /$ day and discontinuation of the MCFG therapy, the anemia improved and the reticulocyte count was restored to normal on hospital day 84 (RBC 336x $10^{4} / \mu \mathrm{L}, \mathrm{Hb} 11.1 \mathrm{~g} / \mathrm{dL}$, reticulocyte count $7 \%$, [23.52×10 / $\mu \mathrm{L}]$ ), after which the patient was finally discharged from the hospital. Thereafter, no recurrence of the normocytic normochromic anemia or relapse of the PRCA was observed.

\section{Discussion}

The most important point that needed to be ascertained in this case was the factors responsible for the acquired PRCA. Drugs reported to have the potential to induce PRCA in- 


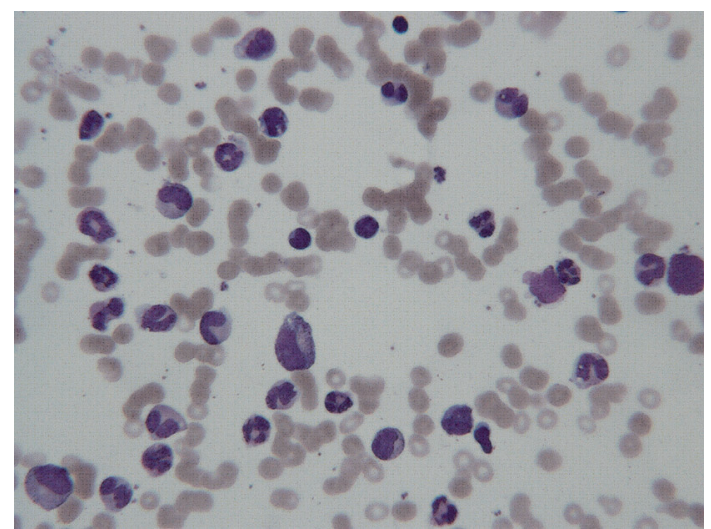

Figure 2A. Bone marrow smear examination following diagnosis of PRCA after the initiation of micafungin treatment. Normocytic normochromic anemia was observed, with adequate leucocytes and platelets, and no abnormal cell was detected (Wright-Giemsa staining; 400x).

clude diphenylhydantoin $(8,9)$, isoniazid $(10,11)$, azathioprine (12) and erythropoietin (13). This patient had received none of these drugs before. Human parvovirus B19 has been reported as a possible cause of chronic PRCA in immunocompromised patients (14). Thymoma, granular lymphocytosis, malignant tumors, and autoimmune diseases have also been reported as possible causes of chronic acquired PRCA $(15,16)$. No evidence of any of these factors was detected in the present patient. MCFG was the only new drug that the patient had been started on before the onset of the acquired chronic PRCA. Furthermore, the PRCA manifested after the dose of MCFG was increased, and no relapse of the PRCA was observed after discontinuation of the drug. Thus, MCFG appears to have been, at least in part, the cause of the PRCA in this case. According to our literature search, no report of acquired PRCA attributable to antifungal agents, including MCFG, has been reported to date, and the present case report seems to be the first such report.

An increased incidence of PRCA among patients with chronic renal failure receiving erythropoietin has recently been reported (13). In the patient presented here, there was no previous history of hemodialysis or erythropoietin administration. However, patients with chronic kidney disease are known to show reduced erythrocytopoiesis (17) and an increase in the prevalence of anemia with a decrease in the GFR $(18,19)$. In addition, the bone marrow function is known to decrease with advancing age (20). The present patient was an elderly patient with stage 3 chronic kidney disease; therefore, it is difficult to rule out the possibility of involvement of these factors in the onset of the PRCA following the initiation of treatment with MCFG. The pathogenesis of drug-induced PRCA is poorly understood, although several hypotheses have been considered, including immune mechanisms, direct metabolic effect, and biochemical predisposition to the toxic effects of certain drugs (21). Ascertaining the existence of a clear-cut relation to the drug awaits further study.

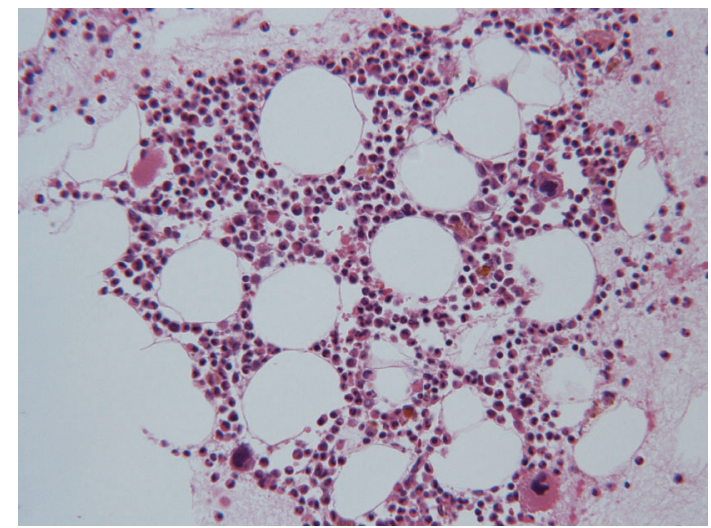

Figure 2B. Bone marrow biopsy of this patient on hospital day 63. There is complete absence of red cell precursors (Hematoxylin and Eosin staining; 200x).

In conclusion, we recently encountered the first and very noteworthy case of acquired PRCA associated with MCFG therapy at our facility. Our experience with this case indicates the necessity of bearing in mind the possibility of previously unknown adverse reactions associated with MCFG treatment.

\section{The authors state that they have no Conflict of Interest (COI).}

\section{References}

1. Tawara S, Ikeda F, Maki $\mathrm{K}$, et al. In vitro activities of a new lipopeptide antifungal agent, FK463, against a variety of clinically important fungi. Antimicrob Agents Chemother 44: 57-62, 2000.

2. Chiou CC, Groll AH, Walsh TJ. New drugs and novel targets for treatment of invasive fungal infections in patients with cancer. Oncologist 5: 120-135, 2000.

3. Hebert MF, Smith HE, Marbury TC, et al. Pharmacokinetics of micafungin in healthy volunteers, volunteers with moderate liver disease, and volunteers with renal dysfunction. J Clin Pharmacol 45: 1145-1152, 2005.

4. Joseph JM, Jain R, Danziger LH. Micafungin: a new echinocandin antifungal. Pharmacotherapy 27: 53-67, 2007.

5. Astellas Pharma US. Mycamine (micafungin sodium) package insert. Deerfield, IL, 2005.

6. Yoshizawa S, Gotoh M, Kitahara $\mathrm{T}$, et al. Micafungin-induced hemolysis attack due to drug-dependent antibody persisting for more than 6 weeks. Leuk Res 34: e60-e61, 2010.

7. Nanri T, Iwanaga E, Fujie S, et al. Micafungin-induced immune hemolysis attack. Int J Hematol 89: 139-141, 2009.

8. Dessypris EN, Redline S, Harris JW, Krantz SB. Diphenylhydantoin-induced pure red cell aplasia. Blood 65: 789794, 1985.

9. Rusia U, Malhotra P, Joshi PJ. Diphenylhydantoin-induced pure red cell aplasia. J. Indian Med Assoc 104: 34-36, 2006.

10. Lewis CR, Manoharan A. Pure red cell hypoplasia secondary to isoniazid. Postgrad Med J 63: 309-310, 1987.

11. Loulergue P, Mir O, Dhote R. Pure red blood cell aplasia and isoniazid use. Emerg Infect Dis 13: 1427-1428, 2007.

12. Agrawal A, Parrott NR, Riad HN, Augustine T. Azathioprineinduced pure red cell aplasia: case report and review. Transplant Proc 36: 2689-2691, 2004.

13. Boven K, Knight J, Bader F, Rossert J, Eckardt KU, Casadevall N. Epoetin-associated pure red cell aplasia in patients with chronic 
kidney disease: solving the mystery. Nephrol Dial Transplant 20S: 33-40, 2005.

14. Raghavachar A. Pure red cell aplasia: review of treatment and proposal for a treatment strategy. Blut 61: 47-51, 1990.

15. Sawada K, Fujishima N, Hirokawa M. Acquired pure red cell aplasia: updated review of treatment. Br J Haematol 142: 505-514, 2008.

16. Casadevall $\mathrm{N}$. What is antibody-mediated pure red cell aplasia (PRCA)? Nephrol Dial Transplant 20 (Suppl 4): iv3-iv8, 2005.

17. Agarwal AK. Practical approach to the diagnosis and treatment of anemia associated with CKD in elderly. J Am Med Dir Assoc 7: S7-S12, 2006.

18. McClellan W, Aronoff SL, Bolton WK, et al. The prevalence of anemia in patients with chronic kidney disease. Curr Med Res Opin 20: 1501-1510, 2004.

19. Hsu CY, McCulloch CE, Curhan GC. Epidemiology of anemia associated with chronic renal insufficiency among adults in the United States: results from the Third National Health and Nutrition Examination Survey. J Am Soc Nephrol 13: 504-510, 2002.

20. Prabhakar M, Ershler WB, Longo DL. Bone marrow, thymus and blood: Changes across the lifespan. Aging Health 5: 385-393, 2009.

21. Yunis AA, Akimura GK, Lutcher CL, Blasquez J, Halloran M. Biochemical lesion in dilantin-induced erythroid aplasia. Blood 30: 587-600, 1967.

(C) 2011 The Japanese Society of Internal Medicine http://www.naika.or.jp/imindex.html 